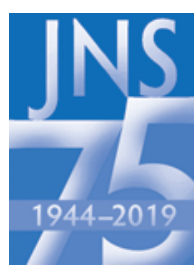

\title{
State of the union: a review of lumbar fusion indications and techniques for degenerative spine disease
}

\author{
JNSPG 75th Anniversary Invited Review Article \\ Patrick C. Reid, MD, Simon Morr, MD, MPH, and Michael G. Kaiser, MD \\ Department of Neurological Surgery, Columbia University, New York, New York
}

\begin{abstract}
Lumbar fusion is an accepted and effective technique for the treatment of lumbar degenerative disease. The practice has evolved continually since Albee and Hibbs independently reported the first cases in 1913, and advancements in both technique and patient selection continue through the present day. Clinical and radiological indications for surgery have been tested in trials, and other diagnostic modalities have developed and been studied. Fusion practices have also advanced; instrumentation, surgical approaches, biologics, and more recently, operative planning, have undergone stark changes at a seemingly increasing pace over the last decade. As the general population ages, treatment of degenerative lumbar disease will become a more prevalent-and costlier-issue for surgeons as well as the healthcare system overall. This review will cover the evolution of indications and techniques for fusion in degenerative lumbar disease, with emphasis on the evidence for current practices.
\end{abstract}

https://thejns.org/doi/abs/10.3171/2019.4.SPINE18915

KEYWORDS lumbar fusion; degenerative spine disease; lumbar spondylosis

\section{$\mathrm{L}$}

UMBAR degenerative disease is a common and debilitating ailment, causing pain and disability in patients and burdening our healthcare system and economy with high and ever-increasing costs. The prevalence of low-back pain due to lumbar spondylosis is estimated at $3.6 \%$ worldwide, and $4.5 \%$ in North America. ${ }^{119}$ Eighty-three million quality-adjusted life years were lost to disability from low-back pain in $2010 .{ }^{58}$ As the population ages, rates of diagnosis and treatment of lumbar degenerative disease have been increasing, and the burden of lumbar spondylosis - both disability and cost—will rise with it.

Lumbar surgery rates have increased steadily over time. ${ }^{90}$ A clear benefit of lumbar fusion surgery has been demonstrated in many patients as evidenced by lowered pain and disability scores and the ability to return to work. However, fusion procedures have not been effective for all patients, and as rates of both disease and treatments have risen, the number of patients undergoing unsuccessful fusion operations has increased as well. ${ }^{55,162}$

Indications for lumbar fusion continue to evolve, in part due to new techniques, technologies, and recent findings in outcomes research. Justification for spinal stabilization has changed as our understanding of lumbar instability and spinal alignment has grown, and outcomes research has more precisely defined those patients who do well with, or without, fusion procedures. Less invasive techniques for fusion procedures have also lowered the threshold for fusion operations in less healthy patients, providing more options for patients who otherwise would be considered too frail for surgery.

New techniques have also developed rapidly, incorporating not only advances in technology but also outcomes research, further refining what we know about the practice of lumbar stabilization. Advances in fixation techniques, approach, biologics, and operative planning have been steady, and will continue to affect the way we treat our patients.

This paper will review and update modern indications and techniques in lumbar fusion for degenerative disease, including the best evidence to support current practices. It will include clinical and radiological indications for fusion, as well as diagnostic modalities for delineating instability and patients with the highest likelihood for signifi-

ABBREVIATIONS ALIF = anterior lumbar interbody fusion; ALL = anterior longitudinal ligament; CFRP = carbon fiber reinforced PEEK; cPS = cortical pedicle screw; LLIF = lateral lumbar interbody fusion; ODI = Oswestry Disability Index; PEEK = polyetheretherketone; PLIF = posterior lumbar interbody fusion; PS = pedicle screw; SPORT = Spine Patient Outcomes Research Trial; TFS = transfacet screw; TL = translaminar; TLIF = transforaminal lumbar interbody fusion.

SUBMITTED March 11, 2019. ACCEPTED April 3, 2019.

INCLUDE WHEN CITING DOI: 10.3171/2019.4.SPINE18915. 
cant improvement following surgery. We will also review modern fixation, including interbody implants, and recent advances in operative planning and navigation.

\section{Indications for Fusion \\ Clinical}

The hallmark symptom of lumbar degenerative disease is low-back pain. Back pain is extremely common, and unfortunately, it is a nonspecific complaint when trying to determine which patients will benefit most from surgery. Historically, moderate back pain has an annual incidence rate of approximately $15 \%$, with $20 \%$ of those patients reporting that the pain is severe enough to prevent them from working. ${ }^{9}$ A careful patient history and physical examination, while rarely definitive, are nonetheless key in determining which patients are most likely to improve with fusion.

Aside from offering guidance in diagnosing degenerative disease-importantly, ruling out more malignant conditions such as infection or neoplasm-a careful history and physical examination will often offer clues as to which patients with spondylosis may benefit from stabilization. The hallmark of mechanical back pain, due to degeneration of the lumbar disc-joint complex, has classically been deep, agonizing pain, exacerbated by loading and relieved by unloading, but other elements of the history and physical are pertinent and have demonstrated some predictive validity for successful operative selection.

There are few randomized trials examining lumbar fusion for degenerative disease. Two studies have shown improvement in chronic back pain (Table 1). Fritzell et al. in 2001 randomized 294 adults with chronic low-back pain for at least 2 years, radiographic evidence of lumbar degeneration between L4 and S1, who had been on "sick leave" from work for at least 1 year, had back pain greater than leg pain, and had high scores on validated, functional disability questionnaires. ${ }^{43}$ The authors excluded patients with radiographic nerve root compression, a history of spine surgery (except discectomy more than 2 years in the past), and "obvious ongoing psychiatric illness." All patients had failed a trial of conservative management. The mean preoperative Oswestry Disability Index (ODI) score of patients randomized to the surgical arm was 47.3, which improved to 35.7 at the 2-year follow-up. This represented a statistically significant improvement over patients randomized to the nonsurgical group (mean ODI score of 48.4 to 45.6 ).

In 2003 Brox et al. conducted a smaller randomized trial, enrolling 64 patients with lumbar spondylosis. ${ }^{19}$ Patients in this trial showed significant postoperative improvement at 1-year follow-up, improving from an ODI of 42.0 to 26.4. To be enrolled, patients needed an ODI score greater than 30 , pain present for more than 1 year, and radiographic evidence of spondylosis. Radiculopathy and psychiatric disease were again among the exclusion criteria.

Both studies showed good results from lumbar fusion. They enrolled only patients with high levels of disability who had already failed conservative management. The average postoperative ODI score remained high in both studies, however, and in the larger study, surgical results
TABLE 1. Studies of fusion for low-back pain

\begin{tabular}{ccc}
\hline $\begin{array}{c}\text { Authors \& } \\
\text { Year }\end{array}$ & $\begin{array}{c}\text { Evidence } \\
\text { Class* }^{*}\end{array}$ & \multicolumn{1}{c}{ Description } \\
\hline $\begin{array}{c}\text { Fritzell et al., } \\
2001\end{array}$ & II & $\begin{array}{c}294 \text { patients w/ lumbar spondylosis ran- } \\
\text { domized to fusion vs conservative care; } \\
\text { surgery significantly better in back pain, } \\
\text { ODI, and return to work }\end{array}$ \\
\hline $\begin{array}{c}\text { Brox et al., } \\
2003\end{array}$ & II & $\begin{array}{l}\text { 64 patients w/ lumbar spondylosis, random- } \\
\text { ized to surgery vs physical and cognitive } \\
\text { therapy; both groups improved, ODI } \\
\text { reduced significantly, with no significant } \\
\text { difference for surgery or conservative } \\
\text { care }\end{array}$ \\
\hline
\end{tabular}

* Levels of evidence assigned based on criteria from Kaiser et al: Guideline update for the performance of fusion procedures for degenerative disease of the lumbar spine. Part 1: Introduction and methodology. J Neurosurg Spine 21:2-6, 2014.

were statistically superior to conservative management. Ultimately, patients with severe disability from back pain can improve with surgery, but the clinical examination is an imprecise tool for selecting these patients.

An aspect of patient history that has consistently predicted patient outcomes is the presence of psychiatric disease, most commonly anxiety or depression. It should be noted that both the Brox and Fritzell studies excluded patients with significant psychiatric comorbidity. Multiple studies have demonstrated that this aspect of the patient history is an independent predictor of outcomes following lumbar fusion surgery. $5.96,143$

The clinical examination is useful in excluding masqueraders of spinal pathology. Low-back pain may be referred from sources other than the lumbar vertebrae, such as the hip or the sacroiliac joint. Twenty to $25 \%$ of patients with low-back pain have some positive findings on provocative testing of the hip joint. ${ }^{115}$ Hip osteoarthritis can be tested with flexion, abduction, and rotation, such as the Faber test. Trochanteric bursitis is another common extraspinal source of back pain: a $20 \%$ rate of greater trochanteric pain syndrome has been reported in patients referred for low-back pain. ${ }^{142}$

\section{Radiological}

The diagnosis of spondylosis is confirmed with imaging. Like clinical back pain, lumbar spondylosis is very common, and not in and of itself a favorable indicator for improvement following fusion procedures. Fritzell and Brox in their prospective studies specifically selected patients with evidence of spondylosis, without nerve compression, and showed good results in an otherwise rigorously selected cohort of patients..$^{19,43}$ Other imaging findings may be more useful in selecting candidates for lumbar fusion.

Radiculopathy and/or back pain resulting from a herniated disc is common. Evidence for fusion in the context of back pain and disc herniation is sparse (Table 2). Takeshima et al. examined 95 patients with disc herniations, 51 of whom had fusion surgery, and 44 with decom- 
TABLE 2. Studies of fusion for a herniated lumbar disc

\begin{tabular}{|c|c|c|}
\hline $\begin{array}{c}\text { Authors \& } \\
\text { Year }\end{array}$ & $\begin{array}{c}\text { Evidence } \\
\text { Class }^{*}\end{array}$ & Description \\
\hline $\begin{array}{c}\text { Takeshima et } \\
\text { al., } 2000\end{array}$ & III & $\begin{array}{l}95 \text { patients w/ lumbar disc herniation } \\
\text { undergoing decompression }(n=44) \\
\text { or decompression and fusion }(n= \\
51) ; \text { retrospective analysis showed no } \\
\text { significant benefit for fusion }\end{array}$ \\
\hline $\begin{array}{c}\text { Fu et al., } \\
2005\end{array}$ & III & $\begin{array}{l}41 \text { patients w/ recurrent disc herniation } \\
\text { underwent discectomy and fusion vs } \\
\text { discectomy alone; no differences in } \\
\text { postop back pain scores at } 88 \text { mos } \\
\text { follow-up }\end{array}$ \\
\hline
\end{tabular}

* Levels of evidence assigned based on criteria from Kaiser et al: Guideline update for the performance of fusion procedures for degenerative disease of the lumbar spine. Part 1: Introduction and methodology. J Neurosurg Spine 21:2-6, 2014.

pression alone. Patients undergoing fusion had better results for low-back pain and recurrence, but overall clinical outcome scores were not significantly different. ${ }^{140}$ Satoh et al. performed a retrospective analysis of patients with disc herniations who underwent either discectomy alone $(\mathrm{n}=147)$ or discectomy and fusion $(\mathrm{n}=78) .{ }^{130}$ Patients undergoing fusion surgery had lower rates of revision and lower low-back pain scores than those undergoing only decompression. Recurrent disc herniations following initial discectomy are more widely considered an indication for fusion, but again, supporting evidence is spare. Fu et al. followed 41 patients with symptomatic recurrent disc herniations who underwent discectomy alone $(\mathrm{n}=21)$ or discectomy and fusion $(n=18)$, who showed no significant difference in outcomes. ${ }^{44} \mathrm{El}$ Shazly et al. published a prospective study in which patients with recurrent herniation were randomized to discectomy or fusion, with superior pain outcomes noted in the fusion group, but no significant difference in overall outcomes and high satisfaction rates in both groups. ${ }^{35}$ Zhou et al. published several studies comparing endoscopic discectomy and fusion for recurrent herniations, none of which showed a statistically significant difference in long-term patient outcomes. ${ }^{85,160,161}$ Due to the increased costs, greater risks, and the lack of compelling evidence of superior outcomes, it is difficult to recommend a lumbar fusion for patients presenting with an uncomplicated lumbar herniated disc. ${ }^{122}$

Spinal stenosis resulting in compression of the lumbar nerves, either in the canal or the neural foramen, is a common indication for surgery. While these patients regularly do well with decompression procedures, in part due to the greater specificity in identifying the location of symptom generation, lumbar fusion for spinal stenosis remains controversial. Chou et al. published a systematic review of 24 studies examining lumbar fusion surgery for spinal stenosis, finding no benefit for fusion surgery over decompression alone. ${ }^{27}$ Uncomplicated stenosis is not considered an indication for lumbar fusion. ${ }^{123}$ The etiology of the stenosis, however, may play a role in the suitability of the patient for a fusion procedure.
TABLE 3. Studies of fusion for stenosis with spondylolisthesis

\begin{tabular}{|c|c|c|}
\hline $\begin{array}{c}\text { Authors \& } \\
\text { Year }\end{array}$ & $\begin{array}{c}\text { Evidence } \\
\text { Class }^{*}\end{array}$ & Description \\
\hline $\begin{array}{l}\text { SPORT } \\
2007,{ }^{154} \\
2009,{ }^{155} \& \\
2018^{3}\end{array}$ & II & $\begin{array}{l}\text { Randomized ( } n=304) \text { and observational } \\
(n=303) \text { patients w/ lumbar spondy- } \\
\text { lolisthesis, surgery vs conservative } \\
\text { care; surgery better in each outcome } \\
\text { measure at 2-, 4-, and 8-year follow-up }\end{array}$ \\
\hline $\begin{array}{c}\text { Ghogawala et } \\
\text { al., } 2016\end{array}$ & I & $\begin{array}{l}66 \text { patients w/ grade I spondylolisthesis } \\
\text { randomized to decompression vs } \\
\text { decompression and fusion; decompres- } \\
\text { sion and fusion significantly improved } \\
\text { quality of life at 4-year follow-up }\end{array}$ \\
\hline $\begin{array}{l}\text { Försth et al., } \\
2016\end{array}$ & II & $\begin{array}{l}247 \text { patients w/ lumbar stenosis ( } 135 \mathrm{w} / \\
\text { spondylolisthesis) randomized to } \\
\text { decompression w/ fusion vs decom- } \\
\text { pression alone; no difference in ODI } \\
\text { or } 6 \text {-minute walk test at 2- and 5-year } \\
\text { follow-up }\end{array}$ \\
\hline $\begin{array}{l}\text { Chou et al., } \\
2009\end{array}$ & II & $\begin{array}{l}\text { Systematic review of } 24 \text { full-text articles on } \\
\text { surgery vs conservative management } \\
\text { for low-back pain and lumbar spondy- } \\
\text { lolisthesis; found surgery equivalent to } \\
\text { intense rehabilitation program }\end{array}$ \\
\hline
\end{tabular}

\begin{abstract}
* Levels of evidence assigned based on criteria from Kaiser et al: Guideline update for the performance of fusion procedures for degenerative disease of the lumbar spine. Part 1: Introduction and methodology. J Neurosurg Spine 21:2-6, 2014
\end{abstract}

The argument for fusion is stronger in patients with lumbar spondylosis/stenosis with evidence of instability (Table 3). Instability from degenerative disease is rarely acute; it is typically glacial, or partial. Radiological signs of instability can be inconsistent, and interpretations vary. A commonly used radiological proxy for instability is spondylolisthesis. Both prospective and retrospective trials have indicated that patients with stenosis due to spondylolisthesis have better outcomes with fusion than with decompression alone. The spondylolisthesis arm of the SPORT (Spine Patient Outcomes Research Trial) represented a large cohort of patients undergoing surgical and conservative treatment, with enrollment of more than 600 patients. ${ }^{154}$ That trial found a benefit for surgery in patients with stenosis and spondylolisthesis. Ninety-five percent of patients in SPORT underwent fusion procedures, $75 \%$ of which were instrumented. Improved outcomes were maintained through 4- and 8-year follow-up. ${ }^{3,155}$ This trial, although large, was complicated by heterogeneity in both patient characteristics and surgical technique. Multiple smaller trials have also demonstrated benefit for fusion surgery in patients with spondylolisthesis. More recently, Ghogawala et al. published a prospective randomized trial comparing patients treated with decompression alone (n $=35)$ to decompression and fusion $(\mathrm{n}=31)$, demonstrating a benefit in those patients undergoing fusion surgery. ${ }^{48}$ Försth et al. published a similarly designed trial demonstrating no benefit for fusion over decompression. ${ }^{41}$ The topic remains controversial. 
Fusion for degenerative deformity is less studied than that for spondylolisthesis, and deformity surgery specifically will be covered by other reviews in this series. Patients with moderate symptoms and significant or progressive sagittal or coronal deformities are generally considered appropriate candidates for lumbar fusion. ${ }^{24}$ Sophisticated parameters have been developed that account for a more global evaluation of spinal mechanics and positioning, including sacropelvic and femoral head position in relation to the upper cervical spine, and even the skull. ${ }^{49,73,74,91}$ Given the mounting evidence linking sagittal balance to outcomes and progression of spinal disease, including adjacent-segment disease, even the degenerative spine surgeon performing a single-level fusion should consider and account for lumbopelvic and global sagittal parameters. ${ }^{95}$

\section{Diagnostic Tests for Evaluation of Back Pain}

Evidence of disc degeneration on MRI can be useful in ruling out disc degeneration as the etiology of low-back pain, but can be nonspecific, especially when determining which patients will benefit from lumbar fusion. Modic endplate changes-demonstrating increased signal in the vertebral body endplate-often correlate with overall degenerative progression in the spine. Although previously reported as a factor in the surgical decision-making process, it is of limited utility when used in isolation. ${ }^{14,94} \mathrm{Di}$ agnostic procedures, used in conjunction with MRI findings, can be useful in guiding management.

Epidural steroid injections are commonly used in the management of radiculopathy but have little evidence to support their use in the management of back pain. ${ }^{152}$ Trigger point injections likewise may have efficacy in treatment of pain from the lumbar musculature, but less in the treatment of spinal degenerative disease. The facet joint is considered to be a pain generator in $15 \%-45 \%$ of patients with low-back pain. ${ }^{133}$ This joint presents an attractive target for focal treatments that can be both therapeutic and diagnostic. Injections of steroids and local anesthetics have resulted in temporary pain relief for properly selected patients. Their use in predicting which patients will benefit from lumbar fusion, however, is less consistent.

Injections into the joint itself have been controversial. Medial nerve blocks, addressing the innervation of the joint, have been more consistent in controlled trials: ${ }^{93}$ multiple randomized controlled trials have shown improvement of ODI and visual analog scale scores. While it is reasonable that these patients would have similar relief following arthrodesis across these presumably symptomatic joints, no studies have yet shown a correlation between relief from a focal facet block and improvement following lumbar fusion.

Discography has been used as a diagnostic test to evaluate potentially pathologic intervertebral discs as pain generators. While some trials have shown an association between concordant pain on discography and improvement following lumbar fusion, several have shown no association, and there is no high-quality evidence in favor of discography as a predictive tool for patient selection. Discoblock, a related procedure in which an anesthetic
TABLE 4. Studies of discoblock as diagnostic tool

\begin{tabular}{ccc}
\hline $\begin{array}{c}\text { Authors \& } \\
\text { Year }\end{array}$ & $\begin{array}{c}\text { Evidence } \\
\text { Class }^{*}\end{array}$ & \multicolumn{1}{c}{ Description } \\
\hline $\begin{array}{c}\text { Ohtori et al., } \\
2009\end{array}$ & II & $\begin{array}{r}42 \text { patients undergoing ALIF underwent } \\
\text { preop discoblock vs discography; those } \\
\text { w/ positive discoblock had significantly } \\
\text { improved pain and disability scores }\end{array}$ \\
\hline
\end{tabular}

* Levels of evidence assigned based on criteria from Kaiser et al: Guideline update for the performance of fusion procedures for degenerative disease of the lumbar spine. Part 1: Introduction and methodology. J Neurosurg Spine 21:2-6, 2014.

agent is injected into the disc, has shown an association with improvement following lumbar fusion. ${ }^{106}$ However, this was only in 1 study, with a small sample size $(n=42)$, and further investigation is needed (Table 4).

\section{Predictive Analytics}

The challenges of executing a randomized controlled study for lumbar surgery are many. Trials are lengthy and expensive, and patient enrollment is difficult. With the widespread use of electronic record keeping, the volume of data available for clinical research has rapidly increased. The use of analytics to identify trends and possible predictive tools for determining patients who will have good (or bad) outcomes from surgery has become more common and will be more widely studied as technologies and techniques for collating, organizing, and interpreting the volume of data are refined.

Significant strides have already been made toward qualifying patients, surgeries, and outcomes in a meaningful way. Frailty indices have been used to quantify the preoperative physiological reserve in patients and predict the likelihood of favorable or unfavorable outcomes in patients undergoing lumbar fusion. The modified frailty index has been applied to patients undergoing lumbar fusion to predict complications, length of stay, readmission, reoperation, and other adverse events. ${ }^{82,108,153}$ Disease-specific predictive tools have been developed to assess patients and inform decision-making, including spine surgery. ${ }^{99,120}$ As more data become available, these predictive tools will become more precise, informative, and useful.

Quantifying the invasiveness of a given surgical procedure is also a useful tool in more uniformly defining that surgery's risks, costs, and benefits. Mirza et al. developed a score to define the invasiveness of a spinal procedure, correlated with blood loss and operative time (Table 5). ${ }^{100}$ More specialized scores have been subsequently developed, and when used in concert with patient frailty, will be a valuable tool in surgical decision-making. These predictive tools are dependent on the quality of data available to them. Databases such as the National Surgical Quality Improvement Program, International Spine Study Group, and National Inpatient Sample provide varying sizes and granularity. As more data become available, more uniform, and more organized, predictive analytics will provide a valuable tool for fields as heterogeneous and complicated as lumbar fusion surgery. 
TABLE 5. Examples of surgical invasiveness scoring

\begin{tabular}{|c|c|c|c|c|c|c|c|}
\hline \multirow[b]{2}{*}{ Procedure } & \multicolumn{3}{|c|}{ Anterior (Score) } & \multicolumn{3}{|c|}{ Posterior (Score) } & \multirow{2}{*}{$\begin{array}{l}\text { Invasiveness } \\
\text { Index Value }\end{array}$} \\
\hline & Decompression & Fusion & Instrumentation & Decompression & Fusion & Instrumentation & \\
\hline L4-5 microdiscectomy & 0 & 0 & 0 & 1 & 0 & 0 & 1 \\
\hline L3-4, 4-5 TLIF, L4-5 laminectomy & 0 & 3 & 3 & 2 & 3 & 3 & 14 \\
\hline $\begin{array}{l}\text { T10-pelvis posterior fusion, L2-4 lami- } \\
\text { nectomy, L4-5 and L5-S1 TLIF }\end{array}$ & 0 & 3 & 3 & 3 & 10 & 10 & 29 \\
\hline Wound debridement & 0 & 0 & 0 & 0 & 0 & 0 & 0 \\
\hline
\end{tabular}

From Mirza et al., 2008. ${ }^{100}$

\section{Lumbar Instrumentation Technologies in Degenerative Disease}

Thoracolumbar instrumentation emerged initially for treatment of idiopathic and neuromuscular deformity. The Harrington rod provided correction in the coronal plane but its inadequacies included sagittal imbalance, flatback syndrome, and persistent vertebral rotational deformity. ${ }^{1}$ The Cotrel-Dubousset system used a bilateral rod construct fixed to segmentally placed laminar hooks, which introduced the attempt at 3D spinal correction. ${ }^{30,31,98} \mathrm{~A}$ multicenter case series using the Cotrel-Dubousset system in degenerative cases with fewer than 5 fused levels revealed improved fusion, pain, and complication outcomes without an increase in neurological dysfunction when compared to historical controls. Soon thereafter, a multicenter trial confirmed statistically significantly improved fusion rates. ${ }^{9}$ Pedicle screw (PS) fixation subsequently replaced the hook system, demonstrating excellent fusion rates compared to previous historical rates in degenerative cases. ${ }^{158}$ PSs are also more robust in 3D manipulation of the vertebral body. ${ }^{47,76,84}$ Current posterolateral fusion techniques include several options.

\section{Hooks}

PSs have largely replaced hook constructs as the pri- mary fixation device for fusion in the spine. ${ }^{16,147}$ Use of hooks at the proximal-end vertebra of long-deformity PS constructs to diminish rates of proximal junctional kyphosis has demonstrated some benefits in several reports and no difference in another series. ${ }^{56,109}$ Use of a mixed laminar hook-PS construct also is preferred in cases of spondylolysis without significant spondylolisthesis where the repair is attempting to fuse across the pars defect and not across vertebral segments. ${ }^{25,66}$

\section{Classic Cancellous Trajectory PSs}

Currently, PSs (Figs. 1 and 2) are the most commonly used form of lumbar spinal fixation, with biomechanical stressors being distributed across all three vertebral body columns. 16,147 Superior fusion rates and outcomes have been consistently, but not universally, demonstrated over noninstrumented fusion. ${ }^{8,40,42,61,79,87,163}$ Current data would suggest PS-related complications are low, reported in less than $3 \%$ of cases. ${ }^{86}$ Although associated with an increased risk of complications, the widespread use of PSs has been justified due to the observed increase in fusion rate and poor outcomes associated with a pseudarthrosis, although definitive evidence of improved outcomes is lacking. . $^{1,145}$ Reported starting trajectories vary for open PS fixation, but are universally lateral to or at the lateral border of the pars interarticularis as it meets the superior articulating process

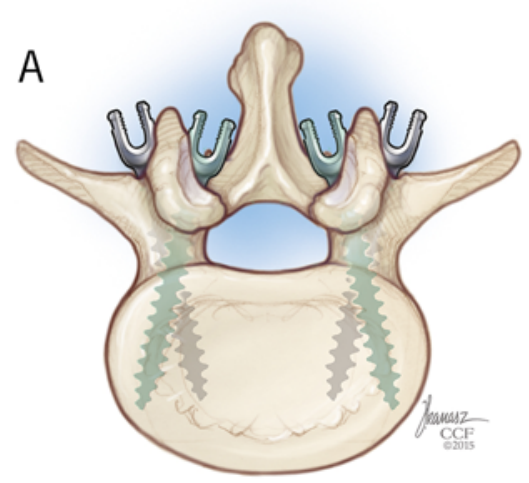

B

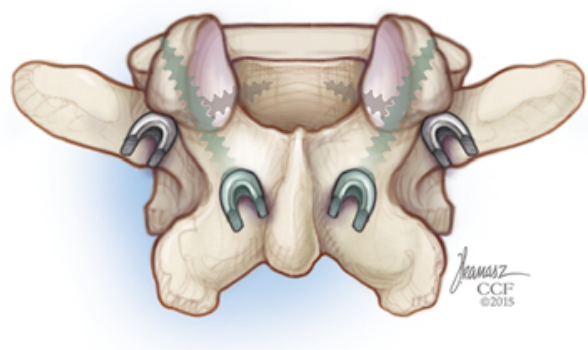

C

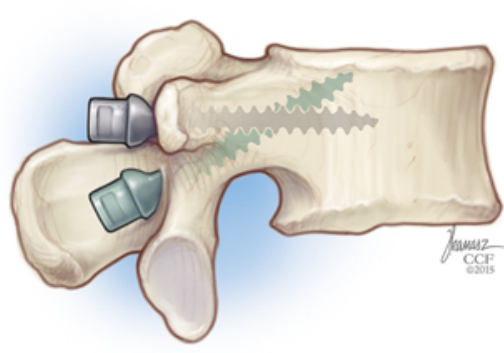

FIG. 1. Axial (A), posterior (B), and lateral (C) schematics demonstrating the trajectories of PSs (gray) and cPSs (green) in a single pedicle. From Mullin JP, Perlmutter B, Schmidt E, Benzel E, Steinmetz MP: Radiographic feasibility study of cortical bone trajectory and traditional pedicle screw dual trajectories. J Neurosurg Spine 25(6):727-732, 2016. Reprinted with permission, Cleveland Clinic Center for Medical Art \& Photography @ 2015-2109. All Rights Reserved. Figure is available in color online only. 

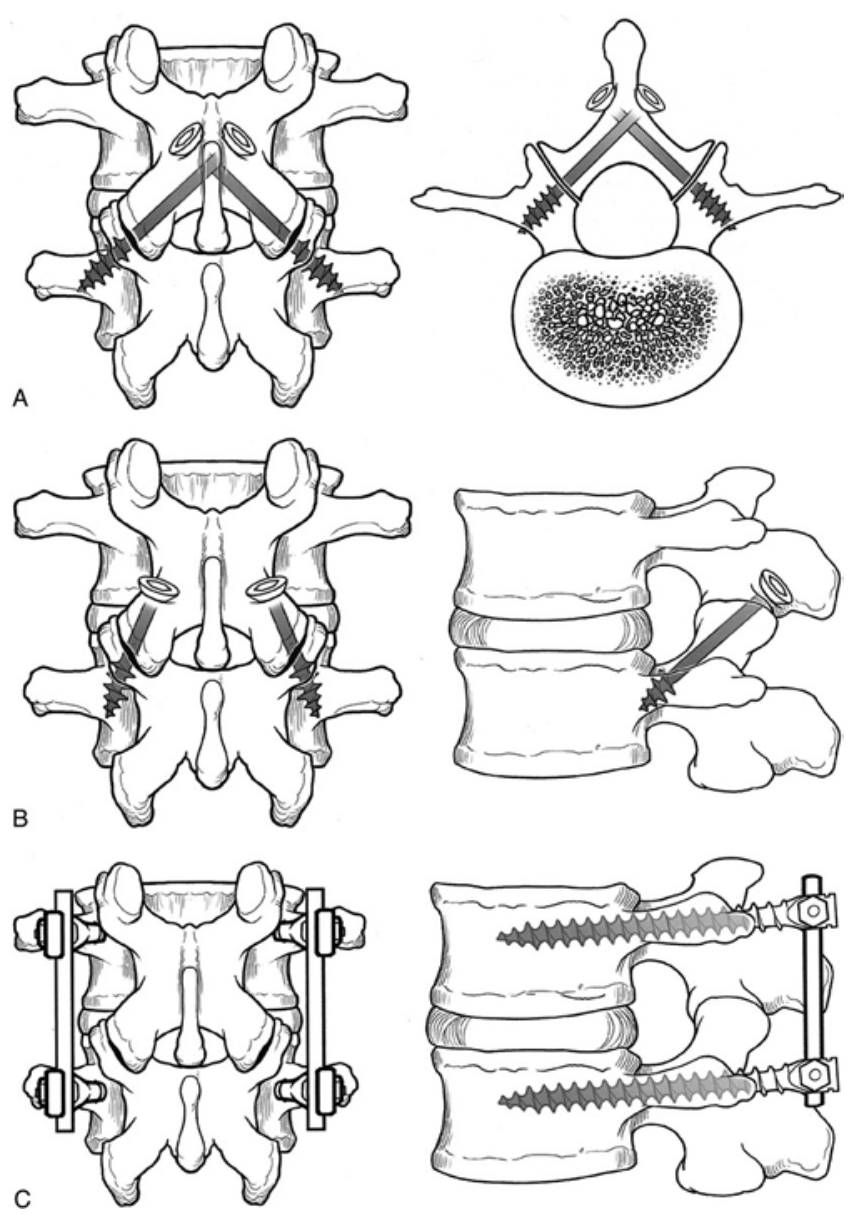

FIG. 2. Demonstrated are TL (A), TFS (B), and PS (C) trajectories. Images obtained with permission from Ferrara LA, Secor JL, Jin $B H$, Wakefield A, Inceoglu S, Benzel EC: A biomechanical comparison of facet screw fixation and pedicle screw fixation: Effects of short-term and long-term repetitive cycling. Spine (Phila Pa 1976) 28(12):1226-1234, 2003 (https://journals.Iww.com/spinejournal/pages/default.aspx).

and the transverse process. A wide dissection is therefore required, with a medialized trajectory toward the prevertebral vascular structures and central neural elements. ${ }^{15,37,105}$ Alternative fixation techniques that require less dissection have therefore been sought with some success. ${ }^{148}$

Percutaneous options for PS placement are numerous and are used for trauma, tumors, deformity, and degenerative processes. Appropriate patient selection is mandatory when utilizing percutaneous PSs for degenerative processes and usually requires inclusion of an interbody grafting, given the limited posterolateral fusion options with percutaneous PS fixation. ${ }^{102}$ Classic techniques include Carm-guided screw placement, which increases the risk of extensive radiation exposure. New navigation, robotic, and computer-assisted techniques are an option for reduced radiation exposure for minimally invasive fusion options. ${ }^{141}$

\section{Cortical Pedicle Screws}

Cortical pedicle screws (cPSs; Fig. 1), first reported in 2009 , start at the inferomedial aspect of the pedicle and are directed inferior-to-superior and medial-to-lateral. They tend to be shorter and of a smaller diameter than traditional PSs. ${ }^{129}$ Cadaveric biomechanical studies reveal marginally higher stiffness in flexion-extension but slightly lower stiffness with lateral bending and axial rotation compared to PSs in conjunction with an interbody graft at one level. ${ }^{110}$ Cortical pedicle screws were noted to be associated with shorter surgical time and decreased blood loss compared with either open or percutaneous PSs, without differences in fusion rates or lordotic correction. Advantages in health-related quality of life measures were also noted in cPSs compared to PSs. Definitive conclusions regarding superiority cannot be made given variable and limited follow-up of less than a year. ${ }^{67}$ Small cohort sizes with 10 or fewer patients in each arm also limit generalizability of the clinical reports. ${ }^{67,101}$ Although CT was performed on each patient, fusion was assessed based on plain radiography, limiting sensitivity for pseudarthrosis. ${ }^{67}$ While some suggestion for improved pullout strength has been reported, most studies have used cPSs in conjunction with an interbody graft. Freehand trajectories have not been adequately characterized and there may be some increased risk of medial breach into the central canal at the proximal insertion site of the screw in examination of cadaveric models. ${ }^{129,148}$

\section{Transfacet Screw Fixation}

Transfacet screw (TFS; Fig. 2) fixation is a relatively shorter lag screw that traverses the facet joint of the levels being fused. It was described in the middle of the last century and has been more recently studied in conjunction with anteriorly or laterally placed interbody devices. ${ }^{17,77}$ Cadaveric biomechanical studies have demonstrated improved rigidity with adjunct facet screw fixation, which may be equivalent to PS adjunct fixation. $39,57,89,103,150,164$ When posterior fixation was placed as a standalone construct without anterior column fixation, PSs were noted to be superior to TFSs in axial rotation and lateral bending, but no difference was noted in flexion and extension. ${ }^{4}$ Unfortunately, the TFS may be limited based on orientation of the facet and an overly vertical facet orientation, which is more common in higher lumbar levels such as L1 and L2, and may make this technique difficult. ${ }^{136}$ Bilateral TFS clinical use has not been reported to date. The use of TFSs contralateral to PSs as an adjunct to an interbody fusion has been reported in small clinical cohort trials with comparable results. Although there may be a trend toward a slightly increased risk of pseudarthrosis with the combined PS and TFS technique, the studies were not powered to establish this conclusion. ${ }^{22,59,134}$

\section{Contralateral Translaminar Fixation}

The translaminar (TL; Fig. 2) screw is intended to start on the inferior spinous process contralaterally and pass through the ipsilateral lamina and through the facet joint. Like the TFS, TL screws lack fixation that spans the middle or anterior column and are therefore usually studied in conjunction with an interbody technique. ${ }^{148}$ Biomechanical reports have been conflicting as TL fixation is either equivalent or slightly less rigid compared to PS fixation when used concomitantly with interbody fixation. ${ }^{36,50,53,113}$ 


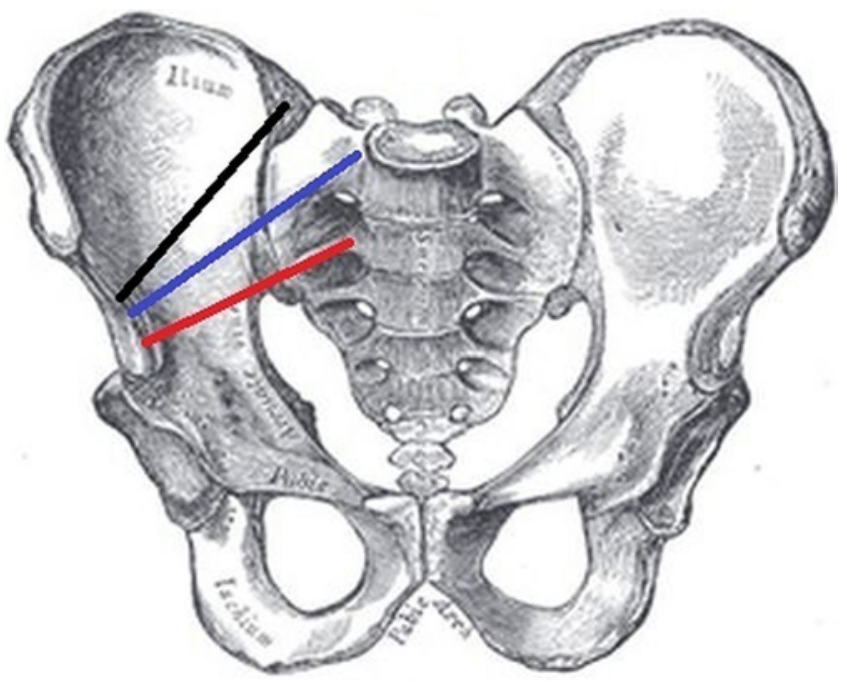

FIG. 3. Demonstrated are the iliac wing (superior, black line), S1-alar iliac (middle, blue line), and S2-alar iliac (inferior, red line) screw trajectories. Images obtained with permission from DePasse JM, Valdes M, Palumbo MA, Daniels AH, Eberson CP: S-1 alar/iliac screw technique for spinopelvic fixation. J Neurosurg Spine 28(5):543-547, 2018. Image adapted from Gray H: Anatomy of the Human Body. Philadelphia: Lea \& Febiger, 1918 (public domain). Figure is available in color online only.

Use in clinical patients has yielded acceptable outcomes, although there are limited studies investigating the efficacy of this technique in lumbar degenerative disease..$^{92}$

\section{Adjunctive Pelvic and Sacropelvic Fixation}

Adjunctive pelvic fixation (Fig. 3) is now considered a favorable technique in lumbosacral fusions where the mechanical stress on the sacral fixation points would increase the risk of failure and development of pseudarthrosis. Mechanical studies have confirmed the excessive strain placed at the base of long constructs and most agree that any lumbosacral fusion starting above L3 should incorporate pelvic fixation. ${ }^{32,111,126}$ The threshold for use of pelvic fixation should be even lower in the presence of anterior column malalignment or manipulation-whether pathologic, as in cases of substantial spondylolisthesis, ${ }^{97,114}$ or iatrogenic, such as in cases of low lumbar 3-column osteotomies. $18,75,137,138$ Historical fixation techniques of the pelvis include Galveston rods, Kostuik intrasacral fixation, and Jackson transiliac fixation. Most modern reports of degenerative, idiopathic, and neuromuscular deformity cases use pelvic screw fixation, which is placed through the iliac wing and directed at the acetabular cortical bone. ${ }^{62}$ Fixation that goes through the sacroiliac joint, such as the $\mathrm{S} 2-$ alar iliac screw, has been described as an option with excellent success, and possibly lower rates of screw fracture and reoperation when compared with iliac wing screw fixation in the adult degenerative population. ${ }^{60,62}$ Advantages of the $\mathrm{S} 2$-alar iliac technique include less dissection of the iliac wing and in-line screw head position with the rest of the lumbosacral PS construct. An S1-alar iliac screw trajectory has also been described but has not been adequately studied, requiring even less dissection of the

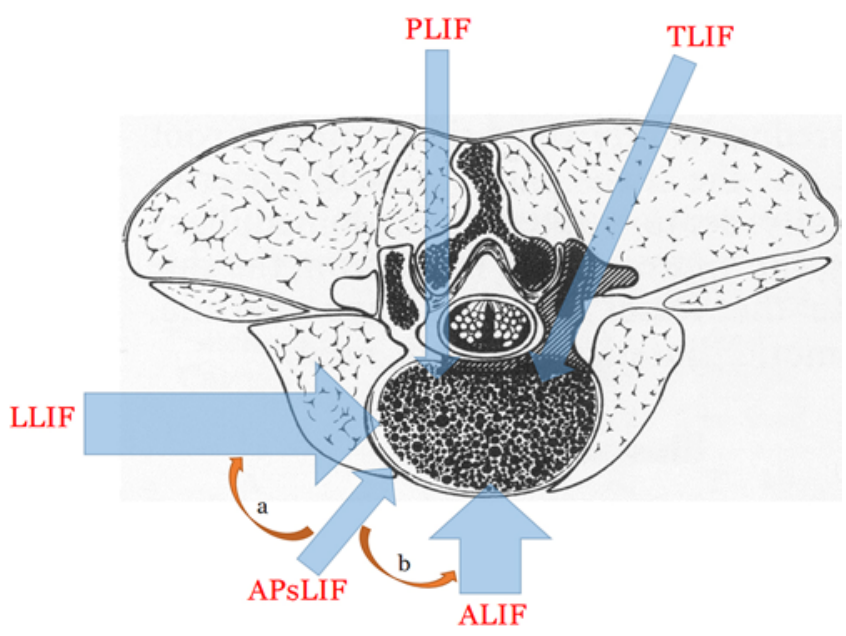

FIG. 4. Demonstrated are the various surgical approaches to the intervertebral disc space. Orthogonal maneuvers of antepsoas lumbar interbody fusion (APSLIF) toward the LLIF (a) and ALIF (b) positions are also described. Image obtained with permission from Larson SJ, Holst RA, Hemmy DC, Sances A Jr: Lateral extracavitary approach to traumatic lesions of the thoracic and lumbar spine. J Neurosurg 45(6):628-637, 1976. Arrows and annotation are added by the current authors. Figure is available in color online only.

sacrum while maintaining in-line alignment. ${ }^{34,151}$ Extensive clinical series are lacking for this technique.

\section{Interbody Technologies in the Degenerative Lumbar Spine}

Interbody fusion with adjunctive posterior fixation in the degenerative lumbar spine has a lower pseudarthrosis and reoperation rate when compared to posterolateral fusion alone. Despite a tendency toward improved functional outcomes as well, this has not been shown to be statistically significant. ${ }^{28}$ Improved sagittal correction has also been reported with interbody grafting compared to standalone posterior techniques, ${ }^{72}$ although this finding could not be reproduced by another group, and may thus be techniquedependent. ${ }^{149}$ Treatment of single-level degenerative spondylolisthesis was reviewed in a meta-analysis of previous retrospective studies, which revealed no statistically significant difference between posterolateral fusion alone and interbody fusion with posterolateral fixation. ${ }^{20}$ Several options for interbody fusion have been described and no definitive superior technique has been demonstrated (Fig. 4). Anterior interbody fusion may provide earlier mobilization and improved function, but the difference does not persist when 2-year outcomes are analyzed. Additionally, anterior fixation with fusion combined with posterior fusion is likely equivalent in outcomes compared to cases that also had a posterolateral fusion performed, with the latter having increased blood loss and operative time. ${ }^{2,104,131}$ The posterior lumbar interbody fusion (PLIF) with bilateral cage placement was shown to be equivalent in fusion rate to the transforaminal lumbar interbody fusion (TLIF) with a unilateral interbody device. A routine bilateral approach is therefore not recommended, as exposing the patient to 
greater risk for iatrogenic dural or nerve root injury cannot be justified based on outcomes. ${ }^{159}$

\section{Structural and Engineering Developments in Devices for Anterior Interbody Insertion}

The anterior interbody device was first described in horses. ${ }^{11,33}$ The evolution of implants has included autografts, allografts, threaded-type cages (usually placed in pairs), and standalone cages with anterior fixation. A variety of anterior fixation options are also available, including an interbody device with a separate unattached plate that spans across the disc space and is fixed by screws into the respective vertebral bodies. The threaded cages were useful in achieving fusion but were superseded by the tapered, wider construction cages that allowed for more robust angular correction. ${ }^{112}$ Several options are available for fixation in the standalone tapered devices. Most commonly, screws or blades are placed into the endplate through an opening in the interbody device. Devices that allow a combination of screw and blade options are also on the market. A new option in wedge-shaped anterior lateral interbody fusion (ALIF) cages includes the possibility to insert a relatively flat implant with the ability to increase the angulation in situ with a "ratcheting" function. These designs have demonstrated more robust angular correction in cadavers. ${ }^{156}$ Well-designed clinical trials and comparisons of the rapidly developing new designs have not yet been performed. ${ }^{112}$

\section{Structural and Engineering Developments in Devices for Posterior Interbody Insertion}

Biomechanical studies reveal that all interbody spacer geometrical alignments have similar rigidity in cadaver models when used concomitantly with posterior pedicle fixation. When studied alone, the asymmetrical, obliquely placed, unilateral TLIF implant was noted to be inferior in lateral bending stiffness when compared to bilateral cages or articulating anteriorly placed cages ${ }^{26,38,144}$ Retrospective clinical studies revealed that old age and central placement of the implant were the biggest predictors of subsidence. ${ }^{46}$ The recommendation is that cages be placed ventrally along the cortical rim. Despite the intended design for "kidney"- or "banana"-type cages to be placed anteriorly, most were indeed inadequately placed in the ventral component and tended to be placed in the central portion of the endplate. ${ }^{46}$ Predictably, laterally expanding TLIF cages were noted to be stiffer than other cages and may even provide as much or greater lateral stiffness as ALIF cages. Multiple models have been described. Most are either delivered in a collapsed state and subsequently expanded and filled with bone graft in situ, or delivered in a straightforward fashion and via use of articulations expanded into a broader footprint in situ. ${ }^{21}$ Posteriorly placed implants provide significantly inferior lordosis correction overall compared to anteriorly placed implants. ${ }^{12}$ Lordosis creation in prone PLIF cases is directly correlated with extent of anterior placement of the implant. ${ }^{80}$ Craniorostrally expanding TLIF cages, which are inserted at a smaller height and are then expanded, have been proposed to achieve further lordosis. Unfortunately, long-term clinical follow-up does not reveal advantages in Cobb angle and, although statisti- cally significant, likely produce clinically inconsequential benefits in disc height. ${ }^{670}$ Nevertheless, several experienced centers have reported improved clinical outcomes with minimal subsidence if the endplates are prepared appropriately. ${ }^{54,127}$ These clinical studies have small sample sizes and do not report extensively on the learning curve required to avoid overexpansion and sufficiently careful endplate preparation without endplate violation. In most cases of posterior interbody implants, bilateral PS fixation is recommended due to its significantly superior rigidity when compared to unilateral PS fixation.?

\section{Developments in Lateral Lumbar Interbody Fusion}

Laterally placed interbody devices have been used safely in the degenerative spine, with most complications being transient and approach-related, including muscular hip-flexion weakness, lumbosacral plexopathy and neurological injury, and vascular injury. ${ }^{135}$ Reported fusion rates range from $85 \%$ to $93 \% .{ }^{13}$ Standalone laterally placed cages have been noted to be less rigid than either augmentation with unilateral or bilateral PSs in biomechanical models. Although a lateral plate provided some increased rigidity, this was noted to be inferior to PS fixation. Bilateral PSs, although more rigid in the axial plane than unilateral PS augmentation of lateral lumbar interbody fusion (LLIF), provide similar reductions in range of motion. Some models have demonstrated lateral plating concomitant with interspinous devices to be equivalent to use of bilateral PS fixation. ${ }^{121,128}$ On average, insertion of a cage through a lateral approach provides between $2.8^{\circ}$ and $5^{\circ}$ of lordosis per level, which is markedly less than anterior techniques that require resection of the anterior longitudinal ligament (ALL) for graft placement, such as the ALIF. ${ }^{88,135}$ Biomechanical studies indicate robust improvement in lordosis correction with concomitant ALL release at the price of introducing substantial instability into the construct. With ALL release, robust concomitant posterior pedicle fixation is recommended. Anterior plating has not proven to restore sufficient stability to the construct. Hyperlordotic cages in the setting of ALL release have been proposed as a substitute to 3 -column posterior osteotomies. ${ }^{69,146}$

\section{Conceptualization of the "Oblique" Antepsoas Approach}

A new option that allows for lateral or anterior access to the interbody space is the antepsoas approach. Theoretical advantages of this approach include lower rates of retrograde ejaculation compared to ALIF, and lower rates of traction nerve injury compared to the transpsoas LLIF approach. ${ }^{65,83}$ With the patient positioned in the lateral position similar to LLIF, dissection is carried anterior to the psoas and lateral to the great vessels. Above L4, where a lateral interbody approach is the preferred method, one performs an "orthogonal maneuver" to position the implants in the same direction as LLIF. At L5-S1 where the vasculature is positioned laterally, the final direction of placement of the implants can mimic that of the ALIF. Both options are possible at $\mathrm{L} 4-5$ and the decision is made based on the particular placement of arterial and venous vasculature ${ }^{29,64}$ Clinical outcomes have been comparable to the ALIF and LLIF approaches. ${ }^{64,83}$ 


\section{Interbody Device Materials}

Interbody device materials vary. Metals include titanium, stainless steel, and cobalt chromium. Plastics include polyetheretherketone (PEEK) and carbon fiber, and carbon fiber-reinforced PEEK (CFRP). All solid metal implants have an elastic modulus that is more than 13 times as strong as cancellous bone. PEEK is closest to cancellous bone, and CFRP is closest to cortical bone. ${ }^{102}$

Microscopic titanium surface roughness increases osteogenic cell differentiation factors in ex vivo experiments. Nanometric roughening of the titanium surface also encourages bone ingrowth and adhesion. Together, these characteristics may improve the osteointegration of titanium-coated implants. Multiple technologies have been attempted, including heat, alkali, and electron beam melting, with success in bone interaction. Electron beam coating of titanium onto PEEK surfaces is also available, with some benefit compared to PEEK alone. ${ }^{118}$ Ex vivo studies show titanium creates an environment supportive of osteoblastic activity in comparison to PEEK, which promotes an inflammatory proapoptotic cellular response ${ }^{107}$ Porous titanium has been used to promote bone integration in the spine as well as for other bony surfaces, such as the acetabulum during arthroplasty. An advantage of this porosity is the decreased modulus, which approached that of PEEK and thus cancellous bone and is therefore suggested to be safer than solid titanium for use in osteoporotic or weakened bone. ${ }^{118}$ Although there are preliminary reports that this would cause a lower chance of subsidence, the sample size is small. ${ }^{45}$ While PEEK does have the advantage of radiolucency, lack of artifact on CT and MRI, and likely lower rates of subsidence, the theoretical bone growth and fusion advantages of titanium have yet to be definitively confirmed ${ }^{63,132}$ Clinical outcomes comparisons have been inconclusive. ${ }^{63}$

Silicon nitride is a ceramic material that is utilized for implants in spinal and other orthopedic products. It is purported to have excellent biointegration and antimicrobial properties, and early reports on its clinical use in cases of infection are now available. ${ }^{117}$ Whereas its use in the anterior cervical fusion cases has been favorably reported in a trial comparison with PEEK,${ }^{10}$ the results from a trial regarding a TLIF ceramic implant in degenerative cases has yet to be reported. ${ }^{68}$

\section{Robotics, Intraoperative Navigation, and Stereotaxy}

Stereotaxy has a long tradition in cranial procedures and surgery, even predating computerized technology. Two primary forms of stereotaxy are currently in use for placement of PSs: intraoperative image-guided infrared navigation with real-time image representation on a computer screen, and robotic trajectory guidance based on a preoperatively selected trajectory on $\mathrm{CT}^{78}$ Randomized controlled trials have reported improved accuracy of PS placement with intraoperative navigation compared to freehand placement. ${ }^{81,116}$ Trials comparing robotic placement to freehand placement have had conflicting results, with one study demonstrating equivalent accuracy to conventional fluoroscopy, with possibly less violation of the facet joint in robotic placement of the screws. ${ }^{71}$ Another study demonstrated inferior screw accuracy and higher rates of screw revision in the robotic arm. ${ }^{124} \mathrm{~A}$ prospective study comparing robotic placement with navigated screw placement was underpowered to allow definitive comparison. ${ }^{125}$ The variable results in cases of robotic screw placement may be due to its more recent introduction into the clinical setting and may reflect differing positions on the learning curve. ${ }^{139}$ Further reports, including studies characterizing the surgeon learning curve, are required as robotic technology becomes more available and familiar.

\section{Evaluation of Fusion}

Surgical exploration is the gold standard for evaluation of fusion, although errors may be observed even when fusion is surgically explored.$^{52} \mathrm{CT}$ is proposed as the best noninvasive imaging modality for evaluation of fusion. ${ }^{52,157}$ Visualization of bony trabeculation across the interspace without any area of bone lucency is consistent with a successful fusion. Conversely, implant subsidence, "haloing" or loosening surrounding screw instrumentation, lucency in areas of bridging bone, and cystic endplate changes are all consistent with a failure of fusion. ${ }^{23}$ Other proposed modalities include MRI, ultrasonography, bone scans, and dynamic plain radiographs. Fusion and pseudarthrosis are clinical conclusions and should be addressed in light of patient symptomatology. ${ }^{52}$

\section{Conclusions}

Lumbar fusion surgery for degenerative conditions has been extensively studied. Although our understanding of indications and outcomes is steadily increasing, rigorous evaluation of indications and characterization of risks and outcomes is still required. Technologies and techniques have proliferated to the great benefit of patients and surgeons. Extensive large and well-designed clinical testing remains to be reported for many new techniques.

\section{References}

1. Aaro S, Dahlborn M: The effect of Harrington instrumentation on the longitudinal axis rotation of the apical vertebra and on the spinal and rib-cage deformity in idiopathic scoliosis studied by computer tomography. Spine (Phila Pa 1976) 7:456-462, 1982

2. Abdu WA, Lurie JD, Spratt KF, Tosteson AN, Zhao W, Tosteson TD, et al: Degenerative spondylolisthesis: does fusion method influence outcome? Four-year results of the spine patient outcomes research trial. Spine (Phila Pa 1976) 34:2351-2360, 2009

3. Abdu WA, Sacks OA, Tosteson ANA, Zhao W, Tosteson TD, Morgan TS, et al: Long-term results of surgery compared with nonoperative treatment for lumbar degenerative spondylolisthesis in the Spine Patient Outcomes Research Trial (SPORT). Spine (Phila Pa 1976) 43:1619-1630, 2018

4. Agarwala A, Bucklen B, Muzumdar A, Moldavsky M, Khalil S: Do facet screws provide the required stability in lumbar fixation? A biomechanical comparison of the Boucher technique and pedicular fixation in primary and circumferential fusions. Clin Biomech (Bristol, Avon) 27:64-70, 2012

5. Alentado VJ, Caldwell S, Gould HP, Steinmetz MP, Benzel EC, Mroz TE: Independent predictors of a clinically significant improvement after lumbar fusion surgery. Spine $\mathbf{J}$ 17:236-243, 2017

6. Alimi M, Shin B, Macielak M, Hofstetter CP, Njoku I Jr, 
Tsiouris AJ, et al: Expandable polyaryl-ether-ether-ketone spacers for interbody distraction in the lumbar spine. Global Spine J 5:169-178, 2015

7. Ambati DV, Wright EK Jr, Lehman RA Jr, Kang DG, Wagner SC, Dmitriev AE: Bilateral pedicle screw fixation provides superior biomechanical stability in transforaminal lumbar interbody fusion: a finite element study. Spine $\mathbf{J}$ 15: 1812-1822, 2015

8. Andersen T, Christensen FB, Niedermann B, Helmig P, Høy K, Hansen ES, et al: Impact of instrumentation in lumbar spinal fusion in elderly patients: 71 patients followed for 2-7 years. Acta Orthop 80:445-450, 2009

9. Andersson GBJ: Epidemiological feature of chronic lowback pain. Lancet 354:581-585, 1999

10. Arts MP, Wolfs JFC, Corbin TP: Porous silicon nitride spacers versus PEEK cages for anterior cervical discectomy and fusion: clinical and radiological results of a singleblinded randomized controlled trial. Eur Spine J 26:23722379, 2017

11. Bagby GW: Arthrodesis by the distraction-compression method using a stainless steel implant. Orthopedics 11:931-934, 1988

12. Barrey C, Darnis A: Current strategies for the restoration of adequate lordosis during lumbar fusion. World J Orthop 6:117-126, 2015

13. Berjano P, Langella F, Damilano M, Pejrona M, Buric J, Ismael M, et al: Fusion rate following extreme lateral lumbar interbody fusion. Eur Spine J 24 (Suppl 3):369-371, 2015

14. Blondel B, Tropiano P, Gaudart J, Huang RC, Marnay T: Clinical results of lumbar total disc arthroplasty in accordance with Modic signs, with a 2-year-minimum follow-up. Spine (Phila Pa 1976) 36:2309-2315, 2011

15. Blumenthal S, Gill K: Complications of the Wiltse Pedicle Screw Fixation System. Spine (Phila Pa 1976) 18:18671871,1993

16. Boden SD: Overview of the biology of lumbar spine fusion and principles for selecting a bone graft substitute. Spine (Phila Pa 1976) 27 (16 Suppl 1):S26-S31, 2002

17. Boucher HH: Method of spinal fusion. Clin Orthop Relat Res (335):4-9, 1997

18. Bridwell KH, Lewis SJ, Lenke LG, Baldus C, Blanke K: Pedicle subtraction osteotomy for the treatment of fixed sagittal imbalance. J Bone Jt Surg Am 85-A:454-463, 2003

19. Brox JI, Sørensen R, Friis A, Nygaard Ø, Indahl A, Keller A, et al: Randomized clinical trial of lumbar instrumented fusion and cognitive intervention and exercises in patients with chronic low back pain and disc degeneration. Spine (Phila Pa 1976) 28:1913-1921, 2003

20. Campbell RC, Mobbs RJ, Lu VM, Xu J, Rao PJ, Phan K: Posterolateral fusion versus interbody fusion for degenerative spondylolisthesis: systematic review and meta-analysis. Global Spine J 7:482-490, 2017

21. Cannestra AF, Peterson MD, Parker SR, Roush TF, Bundy JV, Turner AW: MIS expandable interbody spacers: a literature review and biomechanical comparison of an expandable MIS TLIF with conventional TLIF and ALIF. Spine (Phila Pa 1976) 41 (Suppl 8):S44-S49, 2016

22. Cao Y, Chen Z, Jiang C, Wan S, Jiang X, Feng Z: The combined use of unilateral pedicle screw and contralateral facet joint screw fixation in transforaminal lumbar interbody fusion. Eur Spine J 24:2607-2613, 2015

23. Carreon LY, Djurasovic M, Glassman SD, Sailer P: Diagnostic accuracy and reliability of fine-cut CT scans with reconstructions to determine the status of an instrumented posterolateral fusion with surgical exploration as reference standard. Spine (Phila Pa 1976) 32:892-895, 2007

24. Chen PGC, Daubs MD, Berven S, Raaen LB, Anderson AT, Asch SM, et al: Surgery for degenerative lumbar scoliosis the development of appropriateness criteria. Spine (Phila Pa 1976) 41:910-918, 2016

25. Cheung EV, Herman MJ, Cavalier R, Pizzutillo PD: Spondylolysis and spondylolisthesis in children and adolescents: II. Surgical management. J Am Acad Orthop Surg 14:488-498, 2006

26. Cho W, Wu C, Mehbod AA, Transfeldt EE: Comparison of cage designs for transforaminal lumbar interbody fusion: a biomechanical study. Clin Biomech (Bristol, Avon) 23:979-985, 2008

27. Chou R, Baisden J, Carragee EJ, Resnick DK, Shaffer WO, Loeser JD: Surgery for low back pain: a review of the evidence for an American Pain Society Clinical Practice Guideline. Spine (Phila Pa 1976) 34:1094-1109, 2009

28. Christensen FB, Hansen ES, Eiskjaer SP, Høy K, Helmig P, Neumann P, et al: Circumferential lumbar spinal fusion with Brantigan cage versus posterolateral fusion with titanium Cotrel-Dubousset instrumentation: a prospective, randomized clinical study of 146 patients. Spine (Phila Pa 1976) 27:2674-2683, 2002

29. Chung NS, Jeon CH, Lee HD, Kweon HJ: Preoperative evaluation of left common iliac vein in oblique lateral interbody fusion at L5-S1. Eur Spine J 26:2797-2803, 2017

30. Cotrel Y, Dubousset J: A new technic for segmental spinal osteosynthesis using the posterior approach. Orthop Traumatol Surg Res 100:37-41, 2014

31. Cotrel Y, Dubousset J, Guillaumat M: New universal instrumentation in spinal surgery. Clin Orthop Relat Res 227:10-23, 1988

32. Cunningham BW, Sefter JC, Hu N, Kim SW, Bridwell KH, McAfee PC: Biomechanical comparison of iliac screws versus interbody femoral ring allograft on lumbosacral kinematics and sacral screw strain. Spine (Phila Pa 1976) 35:E198-E205, 2010

33. DeBowes RM, Grant BD, Bagby GW, Gallina AM, Sande $\mathrm{RD}$, Ratzlaff MH: Cervical vertebral interbody fusion in the horse: a comparative study of bovine xenografts and autografts supported by stainless steel baskets. Am J Vet Res 45:191-199, 1984

34. DePasse JM, Valdes M, Palumbo MA, Daniels AH, Eberson CP: S-1 alar/iliac screw technique for spinopelvic fixation. $\mathbf{J}$ Neurosurg Spine 28:543-547, 2018

35. El Shazly AA, El Wardany MA, Morsi AM: Recurrent lumbar disc herniation: a prospective comparative study of three surgical management procedures. Asian J Neurosurg 8:139-146, 2013

36. Eskander M, Brooks D, Ordway N, Dale E, Connolly P: Analysis of pedicle and translaminar facet fixation in a multisegment interbody fusion model. Spine (Phila Pa 1976) 32:E230-E235, 2007

37. Esses SI, Sachs BL, Dreyzin V: Complications associated with the technique of pedicle screw fixation. A selected survey of ABS members. Spine (Phila Pa 1976) 18:22312239, 1993

38. Faizan A, Kiapour A, Kiapour AM, Goel VK: Biomechanical analysis of various footprints of transforaminal lumbar interbody fusion devices. J Spinal Disord Tech 27:E118-E127, 2014

39. Ferrara LA, Secor JL, Jin BH, Wakefield A, Inceoglu S, Benzel EC: A biomechanical comparison of facet screw fixation and pedicle screw fixation: effects of short-term and long-term repetitive cycling. Spine (Phila Pa 1976) 28:1226-1234, 2003

40. Fischgrund JS, Mackay M, Herkowitz HN, Brower R, Montgomery DM, Kurz LT: Degenerative lumbar spondylolisthesis with spinal stenosis: a prospective, randomized study comparing decompressive laminectomy and arthrodesis with and without spinal instrumentation. Spine (Phila Pa 1976) 22:2807-2812, 1997 
41. Försth P, Olafsson G, Carlsson T, Frost A, Borgström F, Fritzell P, et al: A randomized, controlled trial of fusion surgery for lumbar spinal stenosis. N Engl J Med 374:14131423,2016

42. Fritzell $\mathrm{P}$, Hägg O, Wessberg $\mathrm{P}$, Nordwall A: Chronic low back pain and fusion: a comparison of three surgical techniques: a prospective multicenter randomized study from the Swedish lumbar spine study group. Spine (Phila Pa 1976) 27:1131-1141, 2002

43. Fritzell P, Hägg O, Wessberg P, Nordwall A: Lumbar fusion versus nonsurgical treatment for chronic low back pain: a multicenter randomized controlled trial from the Swedish Lumbar Spine Study Group. Spine (Phila Pa 1976) 26:2521-2534, 2001

44. Fu TS, Lai PL, Tsai TT, Niu CC, Chen LH, Chen WJ: Long-term results of disc excision for recurrent lumbar disc herniation with or without posterolateral fusion. Spine (Phila Pa 1976) 30:2830-2834, 2005

45. Fujibayashi S, Takemoto M, Neo M, Matsushita T, Kokubo $\mathrm{T}$, Doi K, et al: A novel synthetic material for spinal fusion: a prospective clinical trial of porous bioactive titanium metal for lumbar interbody fusion. Eur Spine J 20:14861495,2011

46. Fukuta S, Miyamoto K, Hosoe H, Shimizu K: Kidney-type intervertebral spacers should be located anteriorly in cantilever transforaminal lumbar interbody fusion: analyses of risk factors for spacer subsidence for a minimum of 2 years. $\mathbf{J}$ Spinal Disord Tech 24:189-195, 2011

47. Geck MJ, Rinella A, Hawthorne D, Macagno A, Koester L, Sides B, et al: Anterior dual rod versus posterior pedicle fixation surgery for the surgical treatment in Lenke $5 \mathrm{C}$ adolescent idiopathic scoliosis: a multicenter, matched case analysis of 42 patients. Spine Deform 1:217-222, 2013

48. Ghogawala Z, Dziura J, Butler WE, Dai F, Terrin N, Magge SN, et al: Laminectomy plus fusion versus laminectomy alone for lumbar spondylolisthesis. N Engl J Med 374:1424-1434, 2016

49. Glassman SD, Bridwell K, Dimar JR, Horton W, Berven S, Schwab F: The impact of positive sagittal balance in adult spinal deformity. Spine (Phila Pa 1976) 30:2024-2029, 2005

50. Grob D, Humke T: Translaminar screw fixation in the lumbar spine: technique, indications, results. Eur Spine J 7:178-186, 1998

51. Groff MW, Dailey AT, Ghogawala Z, Resnick DK, Watters WC III, Mummaneni PV, et al: Guideline update for the performance of fusion procedures for degenerative disease of the lumbar spine. Part 12: pedicle screw fixation as an adjunct to posterolateral fusion. J Neurosurg Spine 21:7578,2014

52. Gruskay JA, Webb ML, Grauer JN: Methods of evaluating lumbar and cervical fusion. Spine J 14:531-539, 2014

53. Harris BM, Hilibrand AS, Savas PE, Pellegrino A, Vaccaro AR, Siegler S, et al: Transforaminal lumbar interbody fusion: the effect of various instrumentation techniques on the flexibility of the lumbar spine. Spine (Phila Pa 1976) 29:E65-E70, 2004

54. Hawasli AH, Khalifeh JM, Chatrath A, Yarbrough CK, Ray WZ: Minimally invasive transforaminal lumbar interbody fusion with expandable versus static interbody devices: radiographic assessment of sagittal segmental and pelvic parameters. Neurosurg Focus 43(2):E10, 2017

55. Hedlund R, Johansson C, Hägg O, Fritzell P, Tullberg T: The long-term outcome of lumbar fusion in the Swedish lumbar spine study. Spine J 16:579-587, 2016

56. Helgeson MD, Shah SA, Newton PO, Clements DH III, Betz RR, Marks MC, et al: Evaluation of proximal junctional kyphosis in adolescent idiopathic scoliosis following pedicle screw, hook, or hybrid instrumentation. Spine (Phila Pa 1976) 35:177-181, 2010
57. Hou Y, Shen Y, Liu Z, Nie Z: Which posterior instrumentation is better for two-level anterior lumbar interbody fusion: translaminar facet screw or pedicle screw? Arch Orthop Trauma Surg 133:37-42, 2013

58. Hoy D, March L, Brooks P, Blyth F, Woolf A, Bain C, et al: The global burden of low back pain: estimates from the Global Burden of Disease 2010 study. Ann Rheum Dis 73:968-974, 2014

59. Huang P, Wang Y, Xu J, Xiao B, Liu J, Che L, et al: Minimally invasive unilateral pedicle screws and a translaminar facet screw fixation and interbody fusion for treatment of single-segment lower lumbar vertebral disease: surgical technique and preliminary clinical results. J Orthop Surg Res 12:117, 2017

60. Ishida W, Elder BD, Holmes C, Lo SL, Goodwin CR, Kosztowski TA, et al: Comparison between S2-alar-iliac screw fixation and iliac screw fixation in adult deformity surgery: reoperation rates and spinopelvic parameters. Global Spine J 7:672-680, 2017

61. Jäger M, Seller K, Raab P, Krauspe R, Wild A: Clinical outcome in monosegmental fusion of degenerative lumbar instabilities: instrumented versus non-instrumented. Med Sci Monit 9:CR324-CR327, 2003

62. Jain A, Hassanzadeh H, Strike SA, Menga EN, Sponseller PD, Kebaish KM: Pelvic fixation in adult and pediatric spine surgery: historical perspective, indications, and techniques: AAOS exhibit selection. J Bone Joint Surg Am 97:1521-1528, 2015

63. Jain S, Eltorai AE, Ruttiman R, Daniels AH: Advances in spinal interbody cages. Orthop Surg 8:278-284, 2016

64. Jin J, Ryu KS, Hur JW, Seong JH, Kim JS, Cho HJ: Comparative study of the difference of perioperative complication and radiologic results: MIS-DLIF (minimally invasive direct lateral lumbar interbody fusion) versus MISOLIF (minimally invasive oblique lateral lumbar interbody fusion). Clin Spine Surg 31:31-36, 2018

65. Kaiser MG, Haid RW Jr, Subach BR, Miller JS, Smith CD, Rodts GE Jr: Comparison of the mini-open versus laparoscopic approach for anterior lumbar interbody fusion: a retrospective review. Neurosurgery 51:97-105, 2002

66. Kakiuchi M: Repair of the defect in spondylolysis. Durable fixation with pedicle screws and laminar hooks. J Bone Joint Surg Am 79:818-825, 1997

67. Kasukawa Y, Miyakoshi N, Hongo M, Ishikawa Y, Kudo D, Shimada Y: Short-term results of transforaminal lumbar interbody fusion using pedicle screw with cortical bone trajectory compared with conventional trajectory. Asian Spine J 9:440-448, 2015

68. Kersten RF, van Gaalen SM, Arts MP, Roes KC, de Gast A, Corbin TP, et al: The SNAP trial: a double blind multicenter randomized controlled trial of a silicon nitride versus a PEEK cage in transforaminal lumbar interbody fusion in patients with symptomatic degenerative lumbar disc disorders: study protocol. BMC Musculoskelet Disord 15:57, 2014

69. Kim C, Harris JA, Muzumdar A, Khalil S, Sclafani JA, Raiszadeh K, et al: The effect of anterior longitudinal ligament resection on lordosis correction during minimally invasive lateral lumbar interbody fusion: biomechanical and radiographic feasibility of an integrated spacer/plate interbody reconstruction device. Clin Biomech (Bristol, Avon) 43:102-108, 2017

70. Kim CW, Doerr TM, Luna IY, Joshua G, Shen SR, Fu X, et al: Minimally invasive transforaminal lumbar interbody fusion using expandable technology: a clinical and radiographic analysis of 50 patients. World Neurosurg 90:228235,2016

71. Kim HJ, Lee SH, Chang BS, Lee CK, Lim TO, Hoo LP, et al: Monitoring the quality of robot-assisted pedicle screw 
fixation in the lumbar spine by using a cumulative summation test. Spine (Phila Pa 1976) 40:87-94, 2015

72. Kim KT, Lee SH, Lee YH, Bae SC, Suk KS: Clinical outcomes of 3 fusion methods through the posterior approach in the lumbar spine. Spine (Phila Pa 1976) 31:1351-1358, 2006

73. Kim Y: KH B, Lenke LG, YB K, Kim P: Comparative radiographic analysis of the sagittal spinopelvic alignment between 100 asymptomatic adults and 100 patients with sagittal imbalance: the best angular parameters to sagittal vertical axis. Spine (Phila Pa 1976) 10:178-180, 2009

74. Kim YC, Lenke LG, Lee SJ, Gum JL, Wilartratsami S, Blanke KM: The cranial sagittal vertical axis (CrSVA) is a better radiographic measure to predict clinical outcomes in adult spinal deformity surgery than the C7 SVA: a monocentric study. Eur Spine J 26:2167-2175, 2017

75. Kim YJ, Bridwell KH, Lenke LG, Cheh G, Baldus C: Results of lumbar pedicle subtraction osteotomies for fixed sagittal imbalance: a minimum 5-year follow-up study. Spine (Phila Pa 1976) 32:2189-2197, 2007

76. Kim YJ, Lenke LG, Cho SK, Bridwell KH, Sides B, Blanke $\mathrm{K}$ : Comparative analysis of pedicle screw versus hook instrumentation in posterior spinal fusion of adolescent idiopathic scoliosis. Spine (Phila Pa 1976) 29:2040-2048, 2004

77. King D: Internal fixation for lumbosacral fusion. J Bone Joint Surg Am 30A:560-565, 1948

78. Kochanski RB, Lombardi JM, Laratta JL, Lehman RA, O'Toole JE: Image-guided navigation and robotics in spine surgery. Neurosurgery [epub ahead of print], 2019

79. Korsgaard M, Christensen FB, Thomsen K, Hansen ES, Bünger C: The influence of lumbar lordosis on spinal fusion and functional outcome after posterolateral spinal fusion with and without pedicle screw instrumentation. J Spinal Disord Tech 15:187-192, 2002

80. Kwon BK, Berta S, Daffner SD, Vaccaro AR, Hilibrand AS, Grauer JN, et al: Radiographic analysis of transforaminal lumbar interbody fusion for the treatment of adult isthmic spondylolisthesis. J Spinal Disord Tech 16:469-476, 2003

81. Laine T, Lund T, Ylikoski M, Lohikoski J, Schlenzka D: Accuracy of pedicle screw insertion with and without computer assistance: a randomised controlled clinical study in 100 consecutive patients. Eur Spine J 9:235-240, 2000

82. Leven DM, Lee NJ, Kothari P, Steinberger J, Guzman J, Skovrlj B, et al: Frailty index is a significant predictor of complications and mortality after surgery for adult spinal deformity. Spine (Phila Pa 1976) 41:E1394-E1401, 2016

83. Li JX, Phan K, Mobbs R: Oblique lumbar interbody fusion: technical aspects, operative outcomes, and complications. World Neurosurg 98:113-123, 2017

84. Liljenqvist U, Lepsien U, Hackenberg L, Niemeyer T, Halm $\mathrm{H}$ : Comparative analysis of pedicle screw and hook instrumentation in posterior correction and fusion of idiopathic thoracic scoliosis. Eur Spine J 11:336-343, 2002

85. Liu C, Zhou Y: Percutaneous endoscopic lumbar diskectomy and minimally invasive transforaminal lumbar interbody fusion for recurrent lumbar disk herniation. World Neurosurg 98: 14-20, 2017

86. Lonstein JE, Denis F, Perra JH, Pinto MR, Smith MD, Winter RB: Complications associated with pedicle screws. J Bone Joint Surg Am 81:1519-1528, 1999

87. Lorenz M, Zindrick M, Schwaegler P, Vrbos L, Collatz MA, Behal R, et al: A comparison of single-level fusions with and without hardware. Spine (Phila Pa 1976) 16 (8 Suppl):S455-S458, 1991

88. Lykissas MG, Cho W, Aichmair A, Sama AA, Hughes AP, Lebl DR, et al: Is there any relation between the amount of curve correction and postoperative neurological deficit or pain in patients undergoing stand-alone lateral lumbar interbody fusion? Spine (Phila Pa 1976) 38:1656-1662, 2013
89. Mahar A, Kim C, Oka R, Odell T, Perry A, Mirkovic S, et al: Biomechanical comparison of a novel percutaneous transfacet device and a traditional posterior system for single level fusion. J Spinal Disord Tech 19:591-594, 2006

90. Makanji H, Schoenfeld AJ, Bhalla A, Bono CM: Critical analysis of trends in lumbar fusion for degenerative disorders revisited: influence of technique on fusion rate and clinical outcomes. Eur Spine J 27:1868-1876, 2018

91. Makhni MC, Shillingford JN, Laratta JL, Hyun SJ, Kim YJ: Restoration of sagittal balance in spinal deformity surgery. $\mathbf{J}$ Korean Neurosurg Soc 61:167-179, 2018

92. Marchesi DG, Boos N, Zuber K, Aebi M: Translaminar facet joint screws to enhance segmental fusion of the lumbar spine. Eur Spine J 1:125-130, 1992

93. Marks RC, Houston T, Thulbourne T: Facet joint injection and facet nerve block: a randomised comparison in 86 patients with chronic low back pain. Pain 49:325-328, 1992

94. Martínez-Quiñones JV, Aso-Escario J, González-García L, Consolini F, Arregui-Calvo R: Are modic changes able to help us in our clinical practice? A study of the modic changes in young adults during working age. Clin Spine Surg 30:259-264, 2017

95. Matsumoto T, Okuda S, Takafumi M, Yamashita T, Yamasaki R, Sugiura T, et al: Spinopelvic sagittal imbalance as a risk factor for adjacent-segment disease after single-segment posterior lumbar interbody fusion. J Neurosurg Spine 26:435-440, 2017

96. Merrill RK, Zebala LP, Peters C, Qureshi SA, McAnany SJ: Impact of depression on patient-reported outcome measures after lumbar spine decompression. Spine (Phila Pa 1976) 43:434-439, 2018

97. Meyerding HW: Spondylolisthesis. Surg Gynecol Obstet 54:371-377, 1932

98. Michelsen C, Jackson R, Lowe T, Farcy JP, Deinlein D: A multi-center prospective study of the CD Spinal System in patients with degenerative disc disease. J Spinal Disord 11:465-471, 1998

99. Miller EK, Lenke LG, Neuman BJ, Sciubba DM, Kebaish KM, Smith JS, et al: External validation of the Adult Spinal Deformity (ASD) Frailty Index (ASD-FI) in the ScoliRISK-1 Patient Database. Spine (Phila Pa 1976) 43:14261431,2018

100. Mirza SK, Deyo RA, Heagerty PJ, Konodi MA, Lee LA, Turner JA, et al: Development of an index to characterize the "invasiveness" of spine surgery: validation by comparison to blood loss and operative time. Spine (Phila Pa 1976) 33:2651-2662, 2008

101. Mizuno M, Kuraishi K, Umeda Y, Sano T, Tsuji M, Suzuki $\mathrm{H}$ : Midline lumbar fusion with cortical bone trajectory screw. Neurol Med Chir (Tokyo) 54:716-721, 2014

102. Mobbs RJ, Phan K: History of retractor technologies for percutaneous pedicle screw fixation systems. Orthop Surg 8:3-10, 2016

103. Molina C, Kretzer RM, Hu N, Umekoji H, Cunningham BW, Serhan H: Comparative in vitro biomechanical analysis of a novel posterior cervical fixation technique versus conventional posterior-based constructs. J Spinal Disord Tech 27:40-47, 2014

104. Mummaneni PV, Dhall SS, Eck JC, Groff MW, Ghogawala Z, Watters WC III, et al: Guideline update for the performance of fusion procedures for degenerative disease of the lumbar spine. Part 11: interbody techniques for lumbar fusion. J Neurosurg Spine 21:67-74, 2014

105. Oh CH, Yoon SH, Kim YJ, Hyun D, Park HC: Technical report of free hand pedicle screw placement using the entry points with junction of proximal edge of transverse process and lamina in lumbar spine: analysis of 2601 consecutive screws. Korean J Spine 10:7-13, 2013

106. Ohtori S, Kinoshita T, Yamashita M, Inoue G, Yamauchi K, 
Koshi T, et al: Results of surgery for discogenic low back pain: a randomized study using discography versus discoblock for diagnosis. Spine (Phila Pa 1976) 34:1345-1348, 2009

107. Olivares-Navarrete R, Hyzy SL, Slosar PJ, Schneider JM, Schwartz Z, Boyan BD: Implant materials generate different peri-implant inflammatory factors: poly-ether-ether-ketone promotes fibrosis and microtextured titanium promotes osteogenic factors. Spine (Phila Pa 1976) 40:399-404, 2015

108. Ondeck NT, Bohl DD, Bovonratwet P, McLynn RP, Cui JJ, Shultz BN, et al: Discriminative ability of commonly used indices to predict adverse outcomes after poster lumbar fusion: a comparison of demographics, ASA, the modified Charlson Comorbidity Index, and the modified Frailty Index. Spine J 18:44-52, 2018

109. Pahys JM, Vivas AC, Samdani AF, Cunn G, Betz RR, Newton PO, et al: Assessment of proximal junctional kyphosis and shoulder balance with proximal screws versus hooks in posterior spinal fusion for adolescent idiopathic scoliosis. Spine (Phila Pa 1976) 43:E1322-E1328, 2018

110. Perez-Orribo L, Kalb S, Reyes PM, Chang SW, Crawford NR: Biomechanics of lumbar cortical screw-rod fixation versus pedicle screw-rod fixation with and without interbody support. Spine (Phila Pa 1976) 38:635-641, 2013

111. Perra JH: Techniques of instrumentation in long fusions to the sacrum. Orthop Clin North Am 25:287-299, 1994

112. Phan K, Mobbs RJ: Evolution of design of interbody cages for anterior lumbar interbody fusion. Orthop Surg 8:270277, 2016

113. Phillips FM, Cunningham B, Carandang G, Ghanayem AJ, Voronov L, Havey RM, et al: Effect of supplemental translaminar facet screw fixation on the stability of stand-alone anterior lumbar interbody fusion cages under physiologic compressive preloads. Spine (Phila Pa 1976) 29:17311736, 2004

114. Potter BK, Kuklo TR, O'Brien MF: Sacro-iliac fixation for treatment of high-grade spondylolisthesis. Semin Spine Surg 16:119-125, 2004

115. Prather H, Cheng A, Steger-May K, Maheshwari V, Van Dillen L: Hip and lumbar spine physical examination findings in people presenting with low back pain, with or without lower extremity pain. J Orthop Sports Phys Ther 47:163-172, 2017

116. Rajasekaran S, Vidyadhara S, Ramesh P, Shetty AP: Randomized clinical study to compare the accuracy of navigated and non-navigated thoracic pedicle screws in deformity correction surgeries. Spine (Phila Pa 1976) 32:E56-E64, 2007

117. Rambo WM Jr: Treatment of lumbar discitis using silicon nitride spinal spacers: a case series and literature review. Int J Surg Case Rep 43:61-68, 2018

118. Rao PJ, Pelletier MH, Walsh WR, Mobbs RJ: Spine interbody implants: material selection and modification, functionalization and bioactivation of surfaces to improve osseointegration. Orthop Surg 6:81-89, 2014

119. Ravindra VM, Senglaub SS, Rattani A, Dewan MC, Härtl $\mathrm{R}$, Bisson E, et al: Degenerative lumbar spine disease: estimating global incidence and worldwide volume. Global Spine J 8:784-794, 2018

120. Reid DBC, Daniels AH, Ailon T, Miller E, Sciubba DM, Smith JS, et al: Frailty and health-related quality of life improvement following adult spinal deformity surgery. World Neurosurg 112: e548-e554, 2018

121. Reis MT, Reyes PM, Altun I, Newcomb AGUS, Singh V, Chang SW, et al: Biomechanical evaluation of lateral lumbar interbody fusion with secondary augmentation. J Neurosurg Spine 25:720-726, 2016

122. Resnick DK, Choudhri TF, Dailey AT, Groff MW, Khoo
L, Matz PG, et al: Guidelines for the performance of fusion procedures for degenerative disease of the lumbar spine. Part 8: lumbar fusion for disc herniation and radiculopathy. J Neurosurg Spine 2:673-678, 2005

123. Resnick DK, Watters WC III, Mummaneni PV, Dailey AT, Choudhri TF, Eck JC, et al: Guideline update for the performance of fusion procedures for degenerative disease of the lumbar spine. Part 10: lumbar fusion for stenosis without spondylolisthesis. J Neurosurg Spine 21:62-66, 2014

124. Ringel F, Stüer C, Reinke A, Preuss A, Behr M, Auer F, et al: Accuracy of robot-assisted placement of lumbar and sacral pedicle screws: a prospective randomized comparison to conventional freehand screw implantation. Spine (Phila Pa 1976) 37:E496-E501, 2012

125. Roser F, Tatagiba M, Maier G: Spinal robotics: current applications and future perspectives. Neurosurgery $\mathbf{7 2}$ (Suppl 1):12-18, 2013

126. Rosner MK, Ondra SL: Sacropelvic fixation in adult deformity. Semin Spine Surg 16:107-113, 2004

127. Rymarczuk GN, Harrop JS, Hilis A, Härtl R: Should expandable TLIF cages be used routinely to increase lordosis? Clin Spine Surg 30:47-49, 2017

128. Salzmann SN, Shue J, Hughes AP: lateral lumbar interbody fusion-outcomes and complications. Curr Rev Musculoskelet Med 10:539-546, 2017

129. Santoni BG, Hynes RA, McGilvray KC, Rodriguez-Canessa G, Lyons AS, Henson MA, et al: Cortical bone trajectory for lumbar pedicle screws. Spine J 9:366-373, 2009

130. Satoh I, Yonenobu K, Hosono N, Ohwada T, Fuji T, Yoshikawa H: Indication of posterior lumbar interbody fusion for lumbar disc herniation. J Spinal Disord Tech 19:104-108, 2006

131. Schofferman J, Slosar P, Reynolds J, Goldthwaite N, Koestler M: A prospective randomized comparison of 270 degrees fusions to 360 degrees fusions (circumferential fusions). Spine (Phila Pa 1976) 26:E207-E212, 2001

132. Seaman S, Kerezoudis P, Bydon M, Torner JC, Hitchon PW: Titanium vs. polyetheretherketone (PEEK) interbody fusion: meta-analysis and review of the literature. J Clin Neurosci 44:23-29, 2017

133. Sehgal N, Dunbar EE, Shah RV, Colson J: Systematic review of diagnostic utility of facet (zygapophysial) joint injections in chronic spinal pain: an update. Pain Physician 10:213-228, 2007

134. Shao ZX, He W, He SQ, Lin SL, Huang ZY, Tang HC, et al: A 3D navigation template for guiding a unilateral lumbar pedicle screw with contralateral translaminar facet screw fixation: a study protocol for multicentre randomised controlled trials. BMJ Open 7:e016328, 2017

135. Sharma AK, Kepler CK, Girardi FP, Cammisa FP, Huang RC, Sama AA: Lateral lumbar interbody fusion: clinical and radiographic outcomes at 1 year: a preliminary report. $\mathbf{J}$ Spinal Disord Tech 24:242-250, 2011

136. Su BW, Cha TD, Kim PD, Lee J, April EW, Weidenbaum $\mathrm{M}$, et al: An anatomic and radiographic study of lumbar facets relevant to percutaneous transfacet fixation. Spine (Phila Pa 1976) 34:E384-E390, 2009

137. Suk SI, Chung ER, Kim JH, Kim SS, Lee JS, Choi WK: Posterior vertebral column resection for severe rigid scoliosis. Spine (Phila Pa 1976) 30:1682-1687, 2005

138. Suk SI, Chung ER, Lee SM, Lee JH, Kim SS, Kim JH: Posterior vertebral column resection in fixed lumbosacral deformity. Spine (Phila Pa 1976) 30:E703-E710, 2005

139. Sutherland G: Introduction to virtual reality and robotics in neurosurgery. Neurosurgery 72 (Suppl 1):7, 2013

140. Takeshima T, Kambara K, Miyata S, Ueda Y, Tamai S: Clinical and radiographic evaluation of disc excision for lumbar disc herniation with and without posterolateral fusion. Spine (Phila Pa 1976) 25:450-456, 2000 
141. Tanaka M, Sugimoto Y, Arataki S, Takigawa T, Ozaki T: Computer-assisted minimally invasive posterior lumbar interbody fusion without C-arm fluoroscopy. Acta Med Okayama 70:51-55, 2016

142. Tortolani PJ, Carbone JJ, Quartararo LG: Greater trochanteric pain syndrome in patients referred to orthopedic spine specialists. Spine J 2:251-254, 2002

143. Trief PM, Grant W, Fredrickson B: A prospective study of psychological predictors of lumbar surgery outcome. Spine (Phila Pa 1976) 25:2616-2621, 2000

144. Tsitsopoulos PP, Serhan H, Voronov LI, Carandang G, Havey RM, Ghanayem AJ, et al: Would an anatomically shaped lumbar interbody cage provide better stability? An in vitro cadaveric biomechanical evaluation. J Spinal Disord Tech 25:E240-E244, 2012

145. Tsutsumimoto T, Shimogata M, Yoshimura Y, Misawa H: Union versus nonunion after posterolateral lumbar fusion: a comparison of long-term surgical outcomes in patients with degenerative lumbar spondylolisthesis. Eur Spine J 17:1107-1112, 2008

146. Uribe JS, Smith DA, Dakwar E, Baaj AA, Mundis GM, Turner AW, et al: Lordosis restoration after anterior longitudinal ligament release and placement of lateral hyperlordotic interbody cages during the minimally invasive lateral transpsoas approach: a radiographic study in cadavers. J Neurosurg Spine 17:476-485, 2012

147. Vaccaro AR, Garfin SR: Pedicle-screw fixation in the lumbar spine. J Am Acad Orthop Surg 3:263-274, 1995

148. Verma K, Boniello A, Rihn J: Emerging techniques for posterior fixation of the lumbar spine. J Am Acad Orthop Surg 24:357-364, 2016

149. Videbaek TS, Bünger CE, Henriksen M, Neils E, Christensen FB: Sagittal spinal balance after lumbar spinal fusion: the impact of anterior column support results from a randomized clinical trial with an eight- to thirteen-year radiographic follow-up. Spine (Phila Pa 1976) 36:183-191, 2011

150. Volkman T, Horton WC, Hutton WC: Transfacet screws with lumbar interbody reconstruction: biomechanical study of motion segment stiffness. J Spinal Disord 9:425-432, 1996

151. Wang Z, Boubez G, Shedid D, Yuh SJ, Sebaaly A: Is S1 alar iliac screw a feasible option for lumbosacral fixation?: a technical note. Asian Spine J 12:749-753, 2018

152. Watters WC III, Resnick DK, Eck JC, Ghogawala Z, Mummaneni PV, Dailey AT, et al: Guideline update for the performance of fusion procedures for degenerative disease of the lumbar spine. Part 13: injection therapies, low-back pain, and lumbar fusion. J Neurosurg Spine 21:79-90, 2014

153. Weaver DJ, Malik AT, Jain N, Yu E, Kim J, Khan SN: The Modified 5-Item Frailty Index: a concise and useful tool for assessing the impact of frailty on postoperative morbidity following elective posterior lumbar fusions. World Neurosurg 124:e626-e632, 2019

154. Weinstein JN, Lurie JD, Tosteson TD, Hanscom B, Tosteson ANA, Blood EA, et al: Surgical versus nonsurgical treatment for lumbar degenerative spondylolisthesis. $\mathbf{N}$ Engl J Med 356:2257-2270, 2007

155. Weinstein JN, Lurie JD, Tosteson TD, Zhao W, Blood EA, Tosteson ANA, et al: Surgical compared with nonoperative treatment for lumbar degenerative spondylolisthesis. Fouryear results in the Spine Patient Outcomes Research Trial (SPORT) randomized and observational cohorts. J Bone Jt Surg Am 91: 1295-1304, 2009
156. Wilke HJ, Volkheimer D, Robie B, Christensen FB: Twopiece ALIF cage optimizes the bone-implant interface in a 360 setting. Eur Spine J 26:2747-2753, 2017

157. Williams AL, Gornet MF, Burkus JK: CT evaluation of lumbar interbody fusion: current concepts. AJNR Am J Neuroradiol 26:2057-2066, 2005

158. Wood GW II, Boyd RJ, Carothers TA, Mansfield FL, Rechtine GR, Rozen MJ, et al: The effect of pedicle screw/ plate fixation on lumbar/lumbosacral autogenous bone graft fusions in patients with degenerative disc disease. Spine (Phila Pa 1976) 20:819-830, 1995

159. Yan DL, Pei FX, Li J, Soo CL: Comparative study of PILF and TLIF treatment in adult degenerative spondylolisthesis. Eur Spine J 17:1311-1316, 2008

160. Yao Y, Zhang H, Wu J, Liu H, Zhang Z, Tang Y, et al: Comparison of three minimally invasive spine surgery methods for revision surgery for recurrent herniation after percutaneous endoscopic lumbar discectomy. World Neurosurg 100:641-647.e1, 2017

161. Yao Y, Zhang H, Wu J, Liu H, Zhang Z, Tang Y, et al: Minimally invasive transforaminal lumbar interbody fusion versus percutaneous endoscopic lumbar discectomy: revision surgery for recurrent herniation after microendoscopic discectomy. World Neurosurg 99:89-95, 2017

162. Yoshihara H, Yoneoka D: National trends in the surgical treatment for lumbar degenerative disc disease: United States, 2000 to 2009. Spine J 15:265-271, 2015

163. Zdeblick TA: A prospective, randomized study of lumbar fusion. Preliminary results. Spine (Phila Pa 1976) 18:983991, 1993

164. Zhan Y, Tian D: Do translaminar facet screws have the same stability as pedicle screws in two-level anterior lumbar interbody fusion? A biomechanical study. Turk Neurosurg 22:630-633, 2012

\section{Disclosures}

The authors report no conflict of interest concerning the materials or methods used in this study or the findings specified in this paper.

\section{Author Contributions}

Conception and design: all authors. Acquisition of data: Reid, Morr. Analysis and interpretation of data: Reid, Morr. Drafting the article: Reid, Morr. Critically revising the article: Kaiser, Reid. Reviewed submitted version of manuscript: Reid, Morr. Approved the final version of the manuscript on behalf of all authors: Kaiser.

\section{Correspondence}

Michael G. Kaiser: Columbia University, New York, NY.mgk7@ cumc.columbia.edu. 